safety, and second to provide customer services on board. The aim of our study was to determine influence of different psychosocial risk factors on flight attendants work ability.

Methods Field study among cabin crew in Croatia was performed during May 2016. Questionnaires regarding job burnout, workplace stress levels, work ability index (WAI) and socio-demographic questions have been administered to 121 cabin crew in coordination and permission of their trade union. Response rate were $76.8 \%$ giving a total number of 93 participants. Data were analysed using Statistica 12 (http://statistica.io/).

Result Majority $(84.9 \%)$ of participants were women with average age of $40.1 \pm 5.5$ years. More than $2 / 3$ of cabin crew had unsatisfactory WAI score (62/93) and 23 (24.7\%) had low WAI indicating very high priority of adequate preventive measure in work ability preservation. High burnout level had near $50 \%$ of all participants (42/93). Highest negative correlation with WAI score $(\mathrm{r}=-0.625 ; \mathrm{p}<0.001)$ that was confirmed with binary logistic regression model controlled for other socio-demographic variables (OR for burnout score: 1.35; $95 \%$ CI: 1.05 to 1.74 ) showed that higher burnout score is main determinant of low work ability.

Conclusion The occupation of flight attendant is often used as an example of emotional work and due to their work organisation, specific shifts, constant time pressure and responsibility they are highly prone to job burnout. It is imperative to make immediate preventive intervention to reduce levels of burnout among cabin crew and maintain their work ability

\section{TACKLING WORK-RELATED STRESS FACTORS IN LOCAL SELF-GOVERNMENT THROUGH ACTION RESEARCH METHODOLOGY}

'D Mijakoski", 'S Stoleski, ${ }^{2}$ A Talimdzioski, 'J Karadzinska-Bislimovska, 'f Minov, ${ }^{1}$ A Atanasovska, ${ }^{1} \mathrm{~J}$ Babunovski, ${ }^{1} \mathrm{~N}$ Stanceva-Pargov, ${ }^{1} \mathrm{~N}$ Angeleska, ${ }^{1} \mathrm{~A}$ Memedi. ${ }^{1}$ Institute of Occupational Health of RM - WHO CC, Skopje, R. Macedonia; ${ }^{2}$ Local Self-Government, Prilep, R. Macedonia

\subsection{6/oemed-2018-ICOHabstracts. 1630}

Introduction Job demands/resources model of stress assumes that every occupation has its own specific risk factors associated with work-related stress. Action research (AR) allows bottom-up approach where company staff in collaboration with researchers, identifies the most important issues for change within organisational setting, develop, implement, and evaluate context-specific solutions. The aim of the study was to analyse work-related stress factors (job demands) and to draft organisational interventions using AR within local self-government.

Methods AR as a collaborative process (problem identification, planning, implementation, evaluation, and reflection), involving representatives from both self-government and Institute of Occupational Health of RM, was used to generate knowledge and practical solutions to work-related stress factors in local self-government. Actual AR included qualitative study based on focus group (FG) methodology (two FGs, 10 participants in each) with workplace stressors as a main topic of discussion. Within quantitative part of the study, 100 self-government employees (response rate over 80\%) completed surveys (including instruments for measuring job demands and burnout). After planning organisational interventions aimed at tackling emerging work-related stressors, evaluation and reflection phase included collection of outcome and process data.

Results Actual study detected the most important work-related stressors in this self-government (FGs: work in 'ocean' type office, client-related workplace violence, performing several tasks at a same time; Questionnaire data: too much paperwork, low opportunities for professional development, strict hierarchy). Burnout was detected in $17 \%$ employees with significantly higher emotional exhaustion in financial sector $(12.04 \pm 4.7)$ than in fire department $(7.3 \pm 3.8)$ and communal works $(5.8 \pm 3.9) \quad(F=3.55 ; \mathrm{p}=0.011)$. AR team proposed several organisational interventions, including reduction of paperwork, new staff employment, team building activities, communication skills training, redefinition of quantity and quality of workplace tasks, etc.

Discussion Presented AR process is still ongoing and cyclic and includes follow-up activities that are accessible and auditable to team members and other employees.

\section{QUALITY OF WORKING LIFE OF CANCER SURVIVORS: ASSOCIATIONS WITH HEALTH- AND WORK-RELATED VARIABLES}

Angela GEM de Boer*, Merel de Jong, Sietske J Tamminga, Monique HW Frings-Dresen. Academic Medical Centre, Department Coronel Institute of Occupational Health. Amsterdam Public Health research institute, Amsterdam, The Netherlands

\subsection{6/oemed-2018-ICOHabstracts. 1631}

Introduction To measure Quality of Working Life (QWL) among cancer survivors, and to take account of the impact of cancer diagnosis and treatment on a cancer survivors' working life, we developed the self-administered Quality of Working Life Questionnaire for Cancer Survivors (QWLQ-CS). QWL is an important predictor of work continuation. This study aimed to:

- describe the Quality of Working Life (QWL) of cancer survivors, and

- explore associations between the QWL of cancer survivors and health- and work-related variables.

Methods Employed and self-employed cancer survivors were recruited through hospitals and patient organisations. They completed the Quality of Working Life Questionnaire for Cancer Survivors (QWLQ-CS) and health- and work-related variables in a cross-sectional study. The QWL scores of cancer survivors were described and associations between QWL and health- and work-related variables were assessed.

Result The QWLQ-CS was completed by 302 cancer survivors (28\% male) with a mean age of $52 \pm 8$ years. They were diagnosed between 0 and 10 years ago with various types of cancer, such as breast cancer, gastrointestinal cancers, urological cancers and haematological cancers. The QWL mean score of cancer survivors was $75 \pm 12(0-100)$. Cancer survivors had statistically significant lower QWL scores when they had been treated with chemotherapy or when they reported co-morbidity $(\mathrm{p} \leq 0.05)$. Cancer survivors without managerial positions, with low incomes or physically demanding work, and who worked a proportion of their contract hours had statistically significantly lower QWL scores $(\mathrm{p} \leq 0.05)$. 
Discussion This study described the QWL of cancer survivors and associations between QWL and health- and work-related variables. Based on these variables it is possible to indicate groups of cancer survivors who need more attention and support regarding QWL and work continuation.

\section{TOWARDS LEAN, SIX-SIGMA, AND LEAN SIX SIGMA OHS IMPACTS IN UNIVERSITIES}

S Nadeau. École de technologie supérieure, Montreal, Canada

10.1136/oemed-2018-ICOHabstracts. 1632

Introduction Our universities must adapt to increasingly uncertain environments, face fierce international competition, manage budget cuts, increased auditing, rapid technological changes and increasing expectations of various increasingly demanding social partners, and even personalise their academic programs. The 2000s brought interest in lean, six-sigma, and lean six sigma methods. This review of the literature summarises and analyses the documented experience of public and private universities around the world with these approaches.

Methods Scientific databases were queried to retrieve the relevant literature published from 2000 to 2016. The search was completed using the snowball effect. The results were sorted by geographical region, type of process and decisional level. The challenges addressed were also listed and sorted.

Result These approaches are innovative in the university setting. While few results are documented, experiments at American, British, Mexican, Finnish, South African, Indian and Saudi institutions are all on record. Activities in support of teaching and university community services were the principal targets. A single research-related case was retrieved, which dealt with supporting activities.

Discussion Lean, six sigma and lean six sigma methods are not deployed in any systematic way. The principal obstacles are system complexity and the difficulties of adapting the tools to institutional reality and of defining and applying the concepts of client and added value. The few documented measured results are isolated and do not support any generalisation. Impact studies are limited primarily to qualitative statements describing challenges and factors associated with success. No study of the impact of these approaches on the occupational health and safety of university staff was retrieved. Since the lean manufacturing literature mentions frequently both positive (task enrichment, autonomy) and negative (musculoskeletal injuries, stress, fatigue, professional burn-out and others) impacts, it cannot be ruled out that such impacts might be noted also in the university setting.

\section{MANAGEMENT OF STRESS IN THE WORKPLACE: A NATIONAL RESPONSE TO IMPLEMENTING STRESS MANAGEMENT INTERVENTIONS}

${ }^{1}$ Emer Carroll*, ${ }^{2}$ Nodlaig Carroll. ${ }^{1}$ National Health and Safety Function (NHSF), Health Service Executive (HSE), Ireland; ${ }^{2}$ Organisational Psychology Unit, Health Service Executive (HSE), Ireland

\subsection{6/oemed-2018-ICOHabstracts. 1633}

Introduction In 2012, the HSE launched the national 'Policy on Prevention and Management of Stress in the Workplace' which was developed by a cross-sectorial multi-disciplinary group. In line this policy, the Organisational Psychology Unit, local HR (HSE West/North West/Mid West) and National HR designed resources and risk assessment tools to enable managers address workplace stress.

The 2015 European Safety Campaign 'Healthy Workplaces Manage Stress' afforded the HSE an opportunity to develop a national response to workplace stress as a psychosocial risk. The National Health and Safety Function (NHSF) recognised the need for a collaborative response and facilitated the development of a Workplace Stress Working Group (WSG). The WSG compiled of professionals from Organisational Psychology, Health and Safety, Occupational Health $(\mathrm{OH})$, Employee Assistance and Counselling Services (EASC), Learning, Education and Development (LED), Health Promotion (HP and I) and HR.

Methods The WSG developed the HSE's Cycle of Stress Management (Identification, Prevention, Support and Assistance and Monitoring and Review) and created supporting information material.

A seminar programme was developed to:

- provide support and disseminate tools to managers,

- implement workplace stress risk assessment,

- promote manager leadership in pro-actively managing and supporting staff health and wellbeing,

- assess personal health behaviours and

- create supportive positive work environments.

Key stakeholders from the WSG co-presented at these seminars.

Result To date, nineteen accredited seminars were held, with 842 attendees. $95 \%$ of evaluations received $(75 \%$ response rate) were hugely positive.

Data from the NHSF, demonstrated one hospital increased its use of the stress management risk assessment tool by $62.5 \%$, following two stress management seminars.

Discussion Anecdotal evidence suggests that managers are more confident in pro-actively addressing workplace stress and this is evident with the recent results of Health Sector Staff Survey Your Opinion Counts showing that almost 70\% of staff are aware of the facilities to support stress in work.

\section{STRESS, BURNOUT, PSYCHOSOMATIC SYMPTOMS AND THEIR ASSOCIATION WITH WORKING CONDITIONS IN DOCTORS OF HOSPITALS IN MEXICO CITY}

ME Palacios-Nava*, MP Román-Paz. Faculty of Medicine, National Autonomous University of Mexico, Mexico City, Mexico

10.1136/oemed-2018-ICOHabstracts. 1634

Introduction The Burnout syndrome occurs frequently in health care workers. It is associated with stressors present in the medical work. These conditions are different between residents and doctors attached. The objective of this study was to identify the association between working conditions, stress burnout and psychosomatic symptoms in hospital physicians in Mexico.

Methods A cross-sectional study was carried out on a sample of 724 physicians in seven hospitals from Mexico City. An instrument was applied to determine socio-demographic characteristics and working conditions. To evaluate stress, burnout and psychosomatic manifestations, Wolfgang, Maslach and Kroenke inventories were used. They had a reliability of 0.91 , 0.83 and 0.78 respectively 